\title{
Current Status of Laparoscopic and Robotic Pancreatic Surgery and Its Adoption in Singapore
}

\author{
Brian KP Goh, ${ }^{1,2}{ }_{M B B S}$, MMed (Surg), FRCSEd, Roxanne Y Teo, ${ }^{1}{ }_{M B C h B}$
}

\begin{abstract}
Despite the potential clinical advantages offered by laparoscopic pancreatic surgery (LPS), the main obstacle to its widespread adoption is the technically demanding nature of the procedure and its steep learning curve. LPS and robotic pancreatic surgery (RPS) have been proven to result in superior short-term perioperative outcomes and equivalent long-term oncological outcomes compared to the conventional open approach, with the caveat that they are performed by expert surgeons who have been trained to perform such procedures. The primary challenge faced by most pancreatic surgeons is the steep learning curve associated with these complex procedures and the need to undergo surgical training, especially with regards to laparoscopic and robotic pancreaticoduodenectomy. Current evidence suggests that RPS may help to shorten the lengthy learning curve required for LPS. More robust evidence-in the form of large randomised controlled trials-is needed to determine whether LPS and RPS can be safely adopted universally.
\end{abstract}

Ann Acad Med Singapore 2020;49:377-83

Key words: Laparoscopic pancreatectomy, Laparoscopic pancreaticoduodenectomy, Minimally invasive pancreatic surgery, Robotic pancreatectomy, Robotic pancreaticoduodenectomy

\section{Introduction}

Pancreatic surgery is considered one of the most complicated and treacherous procedures in the abdominal cavity since it is associated with high morbidity and mortality rates., ${ }^{1,2}$ Even with major advancements in surgical technique and perioperative care, the morbidity rate of pancreatic surgery in highvolume expert centres remains high at $>50 \%$ even as its mortality rate drops to $<5 \% .^{1-3}$ Consequently, despite the "revolution" - minimally invasive surgery (MIS) - in abdominal surgery that took place in the $1990 \mathrm{~s}$ and early $21^{\text {st }}$ Century, the adoption and practice of MIS in pancreatic surgeries remain limited.
Laparoscopic surgery is associated with several inherent limitations, including diminished haptic feedback, reduced dexterity and decreased natural hand-eye coordination. Any attempt to perform surgery on a patient while observing a 2-dimensional screen is counter-intuitive and compromises hand-eye coordination (fulcrum effect). ${ }^{4,5}$ Furthermore, laparoscopic instruments have a limited range of motion, diminished dexterity and may augment physiological tremor. Consequently, robotic surgery was introduced to overcome the limitations posed by laparoscopic surgery. ${ }^{6,7}$ Until recently, the only roboticassisted surgical platform that was widely available

\footnotetext{
${ }^{1}$ Department of Hepato-pancreato-biliary and Transplant Surgery, Singapore General Hospital, Singapore ${ }^{2}$ Duke-NUS Medical School, Singapore

Address for Correspondence: Prof Brian Goh Kim Poh, Department of Hepato-pancreato-biliary and Transplantation Surgery, Singapore General Hospital, 20 College Road, Level 5 Academia, Singapore 169856.

Email: bsgkp@hotmail.com
} 
around the world was the Da Vinci system offered by Intuitive Surgical, Inc. (Sunnyvale, CA, USA) which offered the advantages of a 3-dimensional view (that offsets the loss of hand-eye coordination in laparoscopic surgery), 7 degrees of freedom that replicate human movement with superior dexterity, elimination of physiological tremor and ergonomic comfort. ${ }^{4,5}$ In theory, the advantages of this robotic platform would translate into superior fine suturing and dissection that are frequently required in major pancreatic surgery, especially pancreaticoduodenectomy (PD) ${ }^{8,9}$

Although the first laparoscopic pancreatic surgery (LPS) was performed in the early $1990 \mathrm{~s},{ }^{10}$ the adoption of LPS remained slow; it was only in the past decade that a significant increase in the adoption of LPS by surgeons from around the world was observed. ${ }^{11}$ Compared to the open approach, LPS is reported to provide the added benefits of smaller incisions with better cosmetic results, lower level of postoperative pain and estimated blood loss, shorter hospital stay and recovery time with equivalent morbidity and overall mortality rate. ${ }^{12-18}$ It is, however, important to emphasise that most of the evidence that supported the use of LPS is limited to retrospective case-control studies, ${ }^{12-18}$ and only 4 randomised controlled trials (RCT) had been performed to date. ${ }^{19-22}$

Despite the clinical advantages offered by LPS, the major obstacle to its widespread adoption is the technically demanding nature of the procedure and its steep learning curve. ${ }^{23}$ This is attributed to the retroperitoneal location of the organ, its proximity to major vasculature and high propensity for complications such as pancreatic fistula and bleeding. Moreover, major pancreatic surgeries are relatively rare procedures in most tertiary health institutions, making it difficult for many surgeons to obtain sufficient case volume to attain proficiency.

\section{Distal Pancreatectomy}

Distal pancreatectomy (DP) is performed for tumours or pathologies that involve the body and tail of the pancreas. ${ }^{2}$ For technical reasons, a concomitant splenectomy is also performed since the splenic artery and vein are closely related to the pancreas with many small branches and tributaries that communicate between the pancreas and these vessels. Since DP is technically more simple to perform than PD, laparoscopic distal pancreatectomy (LDP) is therefore more widely performed than laparoscopic pancreaticoduodenectomy (LPD). ${ }^{5}$ DP has been proposed as an ideal surgical procedure for MIS as unlike $\mathrm{PD}$, it does not require any complex reconstruction. ${ }^{5,24}$

Nonetheless, as a minimally invasive procedure, LDP remains technically challenging and complex, and has been reported to be associated with an open conversion rate of up to $38 \%$ by even reputable high-volume tertiary centres. ${ }^{25}$ Studies have shown that LDP offers several advantages over open surgery, especially in short-term perioperative outcomes including less postoperative pain, quicker recovery and decreased blood loss. ${ }^{12-14,26,27}$ However, most of these studies were retrospective case-control series. In the only RCT (LEOPARD) that compared minimally invasive DP and open DP by the Dutch Pancreatic Cancer Group, Rooij et al found that the former was significantly associated with decreased blood loss and reduced time to functional recovery at the expense of longer operating time. ${ }^{21}$ Similarly, a recent large international cohort study that analysed 1562 minimally invasive DP with $18 \%$ open conversion vs 1359 open DP from the American College of Surgeons National Quality Improvement Program demonstrated a risk reduction rate of $11 \%$ in composite major morbidity. ${ }^{27}$

Although DP is commonly performed with en bloc splenectomy, recent studies have recommended spleen preservation since it reduces the risk of postsplenectomy infection and thrombocytosis, haematologic abnormalities and overall morbidity. ${ }^{28,29}$ Most pancreatic surgeons concur that the spleen should be preserved as far as possible in benign and borderline malignant neoplasms, ${ }^{5,22}$ and 2 techniques have been described for spleen-preserving DP: 1) in the Warshaw technique, the splenic artery and vein are resected, leaving only the short gastric vessels for perfusion of the spleen; and 2) in the Kimura technique, the splenic vessels are spared. ${ }^{5}$ Technically, splenic vessel preservation procedures are more demanding since they require meticulous separation of the splenic vessels from the pancreatic parenchyma and ligation of numerous branches of the splenic vessels supplying the pancreas. Consequently, operating time and blood loss tend to be higher. The Warshaw technique, however, is associated with a higher incidence of splenic infarction and left-sided portal hypertension with gastric varices. ${ }^{24}$

Numerous retrospective studies have shown that a major advantage of robotic distal pancreatectomy (RDP) over LDP is that it offers superior spleen preservation rate. ${ }^{25-34}$ It is hypothesised that improved dexterity of the robotic system facilitates suturing in 
tight spaces and more accurate control of the splenic tributaries, thereby allowing more accurate dissection of splenic vessels from the pancreatic parenchyma. ${ }^{4,5}$ These advantages improve the rate of spleen and splenic vessel preservation in DP.

Another advantage of the robotic platform is the lower open conversion rate to open surgery compared to laparoscopic surgery, especially during the learning phase. ${ }^{35}$ Conversion to the open procedure is undesirable since it mitigates the advantages of MIS, resulting in increased operating time, intraoperative blood loss and need for blood transfusion, higher complication rates and longer hospital stay. ${ }^{25,26,36}$ It is, however, important to emphasise that no RCT has been performed to compare LDP with RDP, and that numerous confounding factors-such as selection bias and learning curve-could have accounted for the findings of these non-randomised studies.

\section{Pancreaticoduodenectomy}

Tumours that are located in the periampullary region require formal resection via $\mathrm{PD}$. As a result of the highly complex manipulations that are required during resection and anastomoses thereafter, the minimally invasive surgical approach is only performed by a few pancreatic surgeons in high-volume centres. ${ }^{37-42} \mathrm{In}$ 1994, Gagner et al ${ }^{10}$ reported the first study of LPD; however, the steep learning curve of LPD led to its slow adoption compared to LDP. Even today, the practice of MIS in PD is limited and remains controversial, given the technical complexity of the procedure and lack of perceived advantages over the open approach.

A few large series of LPD $^{37-9}$ and robotic pancreaticoduodenectomy (RPD) ${ }^{40,41}$ from high-volume centres had reported excellent results associated with MIS. To the best of our knowledge, $3 \mathrm{RCT}^{19,20,22}$ had evaluated short-term outcomes of LPD against open $\mathrm{PD}$, but with mixed results. While 2 single-centre RCT from India and Spain ${ }^{19,20}$ reported short-term benefits associated with LPD including decreased blood loss and shorter hospital stay at the expense of longer operating time, a multicentre RCT from the Netherlands was forced to cease prematurely over concerns of safety after a high mortality rate was observed in the MIS arm. ${ }^{22}$ The findings of these 3 studies suggested that LPD offers advantages over the open approach only when it is performed by experienced surgeons; when LPD is performed by inexperienced surgeons, higher morbidity and even mortality may result. ${ }^{22}$ These findings were corroborated by other single-centre retrospective studies that demonstrated the advantages of MIS when it is performed by more experienced centres, and increased morbidity when MIS is undertaken by less experienced centres. ${ }^{43}$

There is growing evidence that robotic pancreatic surgery (RPS) is potentially superior to LPS, especially for more complex procedures such as PD. A recent multicentre study in North America had shown that RPS was associated with a lower open conversion rate than LPS for both DP and PD. ${ }^{44}$ Another multicentre study in the United States demonstrated that RPS could be practised safely and yielded similar anastomotic and overall complications rates compared to the open approach even during the initial learning phase. ${ }^{45}$ The superior steadiness, precision and dexterity associated with the robotic platform allow fine, accurate dissection and suturing in confined spaces. ${ }^{4,8,9}$ These advantages of the robotic platform will potentially shorten the learning curve for the performance of complex anastomoses in minimally invasive pancreaticoduodenectomy (MIPD) such as pancreatoenteric anastomoses and hepaticojejunostomy compared to conventional laparoscopy. This is especially relevant to minimally invasive hepatopancreatobiliary surgeons who practise in countries that have a small population, and who will never acquire the experience and surgical volumes that surgeons in more populous countries such as China and the United States will have.

\section{Learning Curve in LPS and RPS}

A major obstacle to the widespread adoption of minimally invasive pancreatic surgery (MIPS) especially MIPD - is its steep learning curve. ${ }^{46}$ In the literature, several authors have addressed the learning curve of LDP. Depending on the outcome measure, it was reported to be as low as from 10-15 procedures ${ }^{47,48}$ for open conversion and up to 40 procedures for reduction in operating time. ${ }^{49}$ The learning curve of RDP was reported to be shorter than LDP, ${ }^{50}$ with 2 studies $^{51,52}$ reporting a learning curve of only 5-10 cases for reduction in operating time.

For LPD, a single-surgeon study ${ }^{53}$ that used cumulative sum (CUSUM) chart analysis reported a minimum of 40 procedures before the learning curve - in terms of operating time and blood loss - was completed. Another study from South Korea reported improvements in operating time and postoperative morbidity after approximately 30-60 procedures. ${ }^{54}$ 
Several studies have analysed the learning curve of RPD. The learning curve of a surgeon - in terms of operating time-was reported to range from between $10-33$ procedures. ${ }^{52,55}$ For institutions, the learning curve - in terms of blood loss and conversion ratewas shown to improve after 20 procedures, and 20-80 procedures were needed before an improvement in operating time was seen. ${ }^{56-8}$

The varied findings of different studies have highlighted the difficulty in defining the learning curve of a surgical procedure including MIPS. Various factors can affect this "magic number", including the statistical method used (such as CUSUM), outcome measure (such as blood loss, operating time, morbidity and conversion rate), single surgeon vs institutional data, study cohort size and the surgeon's proficiency and experience in MIS and open surgery. ${ }^{46}$ Consequently, it is almost impossible to determine the exact number of procedures that are required to complete the learning curve in order to achieve proficiency. It is also very unlikely that the personal learning curves of surgeons will be uniform across indivduals. ${ }^{46}$

The inverse association between institution volume and surgical outcomes is well documented in complex surgeries such as pancreatic surgery. ${ }^{23,59,60}$ The volumeoutcome effect is seen in MIPS, especially MIPD. ${ }^{61,62}$ Current data suggest that MIPD is associated with higher mortality in centres that perform $<10$ cases a year. ${ }^{23,46,61,62}$ This finding is especially relevant to many institutions whose pancreatic centres do not see a high volume of procedures, unlike those in China and the United States. To bridge the wide gulf between the open approach and MIPD, several surgeons have proposed a hybrid technique for the learning curve. This technique is shown to be a safe approach that allows surgeons to make the transition from open PD to MIPD. ${ }^{63-6}$

\section{Limitations of RPS}

Despite the theoretical and potential advantages that robotic surgery offers, its widespread use is limited by its high cost that has curtailed accessibility to the robotic platform. ${ }^{8}$ Globally, only a few centres, ${ }^{4,15,31}$ have reported their experiences with RPS. The high cost of acquiring and maintaining this platform has meant that few surgeons from around the world have regular access to this technology for training purposes. This has led to a lack of familiarity and experience with RPS, and few surgeons are willing to attempt complicated robotic procedures such as RPS. It is worthwhile to highlight that with increased adoption and competition, the costs of new technological applications or devices are likely to decrease exponentially with the passage of time.

\section{LPS and RPS in Singapore}

In Singapore, the practice of MIPS had grown in the last decade although most pancreatic surgeries are still being performed using the conventional open approach. Earlier studies had reported exclusively on DP but not PD. In 2009, the first study on LPS was published after it reported on 3 patients who underwent spleen-preserving DP. ${ }^{67}$ Subsequently, larger series on LDP and RDP were published. ${ }^{33,68}$ In 2016, the first study on RPS was published after it reported on 3 cases of spleen-saving, vessel-preserving DP in the Singapore General Hospital (SGH) ${ }^{29}$ In a subsequent update in 2018, SGH reported on its experience with 30 RPS: the open conversion rate was only $3.3 \%$ and the major (Clavien-Dindo grade $>2$ ) morbidity rate was $23.3 \%$ with no mortality. ${ }^{4}$ These findings established the feasibility and safety of RPS.

In recent years, several case series on LPD and RPD were published. In 2019, SGH reported its first case series of 7 RPD. ${ }^{66}$ In a subsequent report of 27 cases of LPD and RPD, ${ }^{9}$ it found that the robotic approach allowed surgeons to make the transition from the hybrid approach to the totally MIS approach more quickly in their learning curves. In the same year, Tan et $a 1^{65}$ reported their experience with laparoscopic-assisted pancreaticoduodenectomy (hybrid approach) and described it as a bridge to the totally MIS approach.

Recently, SGH reported its initial experience with 150 MIPS. ${ }^{69}$ It found a rapid growth in the practice of MIS in the past 6-7 years and $>90 \%$ of procedures were performed since 2012. It also noted an increase in the number of complex MIPS that were performed such as LPD and RPD. In their recent study on robotic hepatopancreatobiliary surgery in Singapore, Lee et $\mathrm{al}^{70}$ reported that as of February 2018, 46 RPSincluding $18 \mathrm{RPD}$-were performed in 2 institutions across Singapore.

Although the number of MIPS is increasing, ${ }^{69}$ most procedures - especially LPD and RPD - are routinely performed by a small number of surgeons. In a small country such as Singapore, the primary challenge faced by pancreatic surgeons is the steep learning curve of these complex procedures and their low numbers. Possible solutions may include centralisation of major pancreatic surgeries in a single centre and the adoption of robotic surgery that has been shown to shorten the learning curve, especially in PD. ${ }^{71}$ Institutions that 
have been performing MIPS should be supported and incentivised to encourage more institutions and pancreatic surgeons to practise MIPS. The introduction of dedicated and structured training programmes and availability of expert proctors are also critical to promote LPS and RPS. ${ }^{23}$

\section{Conclusion}

LPS and RPS are rapidly gaining acceptance and practice from around the world and will undoubtedly become the gold standard in pancreatic surgery in the near future, especially in high-volume pancreatic surgery centres. More large and robust RCT are needed to determine whether LPS and RPS can be safely practised globally.

\section{REFERENCES}

1. He J, Ahuja N, Makary MA, Cameron JL, Eckhauser FE, Choti MA, et al. 2564 resected periampullary adenocarcinomas at a single institution: trends over three decades. HPB (Oxford) 2014;16:83-90.

2. Goh BKP, Tan YM, Chung AYF, Cheow PC, Ong HS, Chan WH, et al. Critical appraisal of 232 consecutive distal pancreatectomies with emphasis on risk factors, outcome, and management of the postoperative pancreatic fistula: a 21-year experience at a single institution. Arch Surg 2008;143:956-65.

3. Hartwig W, Gluth A, Hinz U, Koliogiannis D, Strobel O, Hackert $\mathrm{T}$, et al. Outcomes after extended pancreatectomy in patients with borderline resectable and locally advanced pancreatic cancer. Br J Surg 2016;103:1683-94.

4. Goh BKP, Low TY, Lee SY, Chan CY, Chung AYF, Ooi LLPJ. Initial experience with robotic pancreatic surgery in Singapore: single institution experience with 30 consecutive cases. ANZ J Surg 2019;89:206-10.

5. Teo RYA, Goh BKP. Surgical resection of pancreatic neuroendocrine neoplasm by minimally invasive surgery-the robotic approach? Gland Surg 2018;7:1-11.

6. Leong QM, Kim SH. Robot-assisted rectal surgery for malignancy: a review of current literature. Ann Acad Med Singapore 2011;40:460-6.

7. Ng JS, Fong YF, Tong PS, Yong EL, Low JJH. Gynaecologic robot-assisted cancer and endoscopic surgery (GRACES) in a tertiary referral centre. Ann Acad Med Singapore 2011;40:208-12.

8. Goh BKP, Low TY, Teo JY, Lee SY, Chan CY, Chung AYF, et al. Initial single institution experience with robotic biliary surgery and bilio-enteric anastomosis in Southeast Asia. ANZ J Surg 2019; 89:E142-6.

9. Goh BKP, Low TY, Kam JH, Lee SY, Chan CY. Initial experience with laparoscopic and robotic surgery for the treatment of periampullary tumours: single institution experience with the first 30 consecutive cases. ANZ J Surg 2019;89:E137-41.

10. Gagner M, Pomp A. Laparoscopic pylorus-preserving pancreatoduodenectomy. Surg Endosc 1994;8:408-10.

11. Peng L, Lin S, Li Y, Xiao W. Systematic review and meta-analysis of robotic vs open pancreaticoduodenectomy. Surg Endosc 2017;31:3085-97.
12. Mehrabi A, Hafezi M, Arvin J, Esmaeilzadeh M, Garoussi C, Emami $\mathrm{G}$, et al. A systematic review and meta-analysis of laparoscopic versus open distal pancreatectomy for benign and malignant lesions of the pancreas: it's time to randomize. Surgery 2015;157:45-55.

13. Pericleous S, Middleton N, McKay SC, Bowers KA, Hutchins RR. Systematic review and meta-analysis of case-matched studies comparing open and laparoscopic distal pancreatectomy: is it a safe procedure? Pancreas 2012;41:993-1000.

14. Venkat R, Edil BH, Schulick RD, Lidor AO, Makary MA, Wolfgang CL. Laparoscopic distal pancreatectomy is associated with significantly less overall morbidity compared to the open technique: a systematic review and meta-analysis. Ann Surg 2012;255:1048-59.

15. Kamarajah SK, Bundred JR, Marc OS, Jiao LR, Hilal MA, Manas $\mathrm{DM}$, et al. A systematic review and network meta-analysis of different surgical approaches for pancreaticoduodenectomy. HPB (Oxford) 2020;22:329-39.

16. Jusoh AC, Ammori BJ. Laparoscopic versus open distal pancreatectomy: a systematic review of comparative studies. Surg Endosc 2012;26:904-13.

17. Nakamura M, Nakashima H. Laparoscopic distal pancreatectomy and pancreatoduodenectomy: is it worthwhile? A meta-analysis of laparoscopic pancreatectomy. J Hepatobiliary Pancreat Sc 2013;20:421-8.

18. Xie K, Zhu YP, Xu XW, Chen K, Yan JF, Mou YP. Laparoscopic distal pancreatectomy is as safe and feasible as open procedure: a meta-analysis. World J Gastroenterol 2012;18:1959-67.

19. Palanivelu C, Senthilnathan P, Sabnis SC, Babu NS, Gurumurthy SS, Vijai NA, et al. Randomized clinical trial of laparoscopic versus open pancreatoduodenectomy for periampullary tumours. Br J Surg 2017; 104:1443-50.

20. Poves I, Burdío F, Morató O, Iglesias M, Radosevic A, Ilzarbe L, et al. Comparison of perioperative outcomes between laparoscopic and open approach for pancreatoduodenectomy: the PADULAP randomized controlled trial. Ann Surg 2018;268:731-9.

21. De Rooij T, Van Hilst J, Van Santvoort H, Boerma D, van den Boezem P, Daams F, et al. Minimally invasive versus open distal pancreatectomy (LEOPARD): a multicenter patient-blinded randomized controlled trial. Ann Surg 2019;269:2-9.

22. Van Hilst J, De Rooij T, Bosscha K, Brinkman DJ, Van Dieren S, Dijkgraaf MG, et al. Laparoscopic versus open pancreatoduodenectomy for pancreatic or periampullary tumours (LEOPARD-2): a mulitcentre, patient-blinded, randomised controlled phase 2/3 trial. Lancet Gastroenterol Hepatol 2019;4:199-207.

23. Asbun HJ, Moekotte AL, Vissers FL, Kunzler F, Cipriani F, Alseidi A, et al. The Miami International Evidence-based Guidelines for minimally invasive pancreas resection. Ann Surg 2020;271:1-14.

24. Goh BKP, Kabir T, Koh YX, Teo JY, Lee SY, Kam JH, et al. External validation of the Japanese difficulty scoring system for minimally-invasive distal pancreatectomies. Am J Surg 2019; 218:967-71.

25. Lee SY, Allen PJ, Sadot E, D’Angelica MI, DeMatteo RP, Fong Y, et al. Distal pancreatectomy: a single institution's experience in open, laparoscopic, and robotic approaches. J Am Coll Surg 2015;220:18-27.

26. Gavriilidis P, Roberts KJ, Sutcliffe RP. Comparison of robotic vs laparoscopic vs open distal pancreatectomy. A systematic review and network meta-analysis. HPB (Oxford) 2019;21:1268-76.

27. Klompmaker S, De Rooij T, Koerkamp BG, Shankar AH, Siebert $\mathrm{U}$, Besselink $\mathrm{MG}$, et al. International validation of reduced major 
morbidity after minimally invasive distal pancreatectomy compared with open pancreatectomy. Ann Surg 2019;doi:10.1097/ SLA.0000000000003659.

28. Cienfuegos JA, Salguero J, Núñez-Córdoba JM, Ruiz-Canela M, Benito A, Ocaña S, et al. Short- and long-term outcomes of laparoscopic organ-sparing resection in pancreatic neuroendocrine tumors: a single-center experience. Surg Endosc 2017;31:3847-57.

29. Goh BKP, Wong JS, Chan CY, Cheow PC, Ooi LLPJ, Chung AYF. First experience with robotic spleen-saving vessel-preserving distal pancreatectomy in Singapore: a report of three consecutive cases. Singapore Med J 2016;57:464-9.

30. Jain G, Chakravartty S, Patel AG. Spleen-preserving distal pancreatectomy with and without splenic vessel ligation: a systematic review. HPB (Oxford) 2013;15:403-10.

31. Hu YH, Qin YF, Yu DD, Li X, Zhao YM, Kong DJ, et al. Meta-analysis of short-term outcomes comparing robot-assisted and laparoscopic distal pancreatectomy. J Comp Eff Res 2020;9:201-18.

32. Kang CM, Kim DH, Lee WJ, Chi HS. Conventional laparoscopic and robot-assisted spleen-preserving pancreatectomy: does Da Vinci have clinical advantages? Surg Endosc 2011;25:2004-9.

33. Goh BKP, Chan CY, Soh HL, Lee SY, Cheow PC, Chow PKH, et al. A comparison between robotic-assisted laparoscopic distal pancreatectomy versus laparoscopic distal pancreatectomy. Int J Med Robot 2017;13:doi:10.1002/rcs. 1733.

34. Liu R, Liu Q, Zhao ZM, Tan XL, Gao YX, Zhao GD. Robotic versus laparoscopic distal pancreatectomy: a propensity score-matched study. J Surg Oncol 2017;116:461-9.

35. Niu X, Yu B, Yao L, Tian J, Guo T, Ma S, et al. Comparison of surgical outcomes of robot-assisted laparoscopic distal pancreatectomy versus laparoscopic and open resections: a systematic review and metaanalysis. Asian J Surg 2019;42:32-45.

36. Chen S, Zhan Q, Chen JZ, Jin JB, Deng XX, Chen H, et al. Robotic approach improves spleen-preserving rate and shortens postoperative hospital stay of laparoscopic distal pancreatectomy: a matched cohort study. Surg Endosc 2015;29:3507-18.

37. Palanivelu C, Rajan PS, Rangarajan M, Vaithiswaran V, Senthilnathan $\mathrm{P}$, Parthasarathi R, et al. Evolution in techniques of laparoscopic pancreaticoduodenectomy: a decade long experience from a tertiary center. J Hepatobiliary Pancreat Surg 2009;16:731-40

38. Kendrick ML, Cusati D. Total laparoscopic pancreaticoduodenectomy: feasibility and outcome in an early experience. Arch Surg 2010;145:19-23.

39. Song KB, Kim SC, Lee W. Laparoscopic pancreaticoduodenectomy for periampullary tumors: lessons learned from 500 consecutive patients in a single center. Surg Endosc 2020;34:1343-52.

40. Zureikat AH, Beane JD, Zenati MS, Abbas AIA, Boone BA, Moser AJ, et al. 500 minimally invasive robotic pancreatoduodenectomies: one decade of optimizing performance. Ann Surg 2019; doi:10.1097/ SLA.0000000000003550.

41. Shi Y, Wang W, Qiu W, Zhao S, Wang J, Weng Y, et al. Learning curve from 450 cases of robot-assisted pancreaticoduodenectomy in a high-volume pancreatic center: optimization of operative procedure and a retrospective study. Ann Surg 2019;doi:10.1097/ SLA.0000000000003664.

42. Liu R, Zhao GD, Tang WB, Zhang KD, Zhao ZM, Gao YX, et al. A single-team experience with robotic pancreatic surgery in 1010 cases. Nan Fang Yi Ke Da Xue Xue Bao 2018;38:130-4.

43. Dokmak S, Ftériche FS, Aussilhou B, Bensafta Y, Lévy P, Ruszniewski $\mathrm{P}$, et al. Laparoscopic pancreaticoduodenectomy should not be routine for resection of periampullary tumors. J Am Coll Surg $2015 ; 220: 831-8$.
44. Nassour I, Wang SC, Porembka MR, Yoop AC, Choti MA, Ausgustine $\mathrm{MM}$, et al. Robotic versus laparoscopic pancreaticoduodenectomy: a NSQIP analysis. J Gastrointest Surg 2017;21:1784-92.

45. Watkins AA, Kent TS, Gooding WE, Boggi U, Chalikonda S, Kendrick $\mathrm{ML}$, et al. Multicenter outcomes of robotic reconstruction during the early learning curve for minimally-invasive pancreaticoduodenectomy. HPB (Oxford) 2018;20:155-65.

46. Moekotte AL, Rawashdeh A, Asbun HJ, Coimbra FJ, Edil BH, Jarufe N, et al. Safe implementation of minimally invasive pancreas resection: a systematic review. HPB (Oxford) 2020;22:637-48.

47. Braga M, Ridolfi C, Balzano G, Castoldi R, Pecorelli N, Di Carlo V. Learning curve for laparoscopic distal pancreatectomy in a high-volume hospital. Updates Surg 2012;64:179-83.

48. Hua Y, Javed AA, Burkhart RA, Makary MA, Weiss MJ, Wolfgang $\mathrm{CL}$, et al. Preoperative risk factors for conversion and learning curve of minimally invasive distal pancreatectomy. Surgery 2017;162:1040-7.

49. Dokmak S, Ftériche FS, Aussilhou B, Lévy P, Ruszniewski P, Cros J, et al. The largest European single-center experience: 300 laparoscopic pancreatic resections. J Am Coll Surg 2017;225:226-34.

50. Daouadi M, Zureikat AH, Zenati MS, Choudry H, Tsung A, Bartlett $\mathrm{DL}$, et al. Robot-assisted minimally invasive distal pancreatectomy is superior to the laparoscopic technique. Ann Surg 2013;257:128-32.

51. Napoli N, Kauffmann EF, Perrone VG, Miccoli M, Brozzetti S, Boggi U. The learning curve in robotic distal pancreatectomy. Updates Surg 2015;67:257-64.

52. Takahashi C, Shridhar R, Huston J, Meredith K. Outcomes associated with robotic approach to pancreatic resections. J Gastrointest Oncol 2018;9:936-41

53. Wang M, Meng L, Cai Y, Li Y, Wang X, Zhang Z, et al. Learning curve for laparoscopic pancreaticoduodenectomy: a CUSUM analysis. J Gastrointest Surg 2016;20:924-35.

54. Kim SC, Song KB, Jung YS, Kim YH, Park DH, Lee SS, et al. Shortterm clinical outcomes for 100 consecutive cases of laparoscopic pylorus-preserving pancreatoduodenectomy: improvement with surgical experience. Surg Endosc 2013;27:95-103.

55. Napoli N, Kauffmann EF, Palmeri M, Miccoli M, Costa F, Vistoli F, et al. The learning curve in robotic pancreaticoduodenectomy. Dig Surg 2016;33:299-307.

56. Boone BA, Zenati M, Hogg ME, Steve J, Moser AJ, Bartlett DL, et al. Assessment of quality outcomes for robotic pancreaticoduodenectomy: identification of the learning curve. JAMA Surg 2015;150:416-22.

57. Chen S, Chen JZ, Zhan Q, Deng XX, Shen BY, Peng CH, et al. Robot-assisted laparoscopic versus open pancreaticoduodenectomy: a prospective, matched, mid-term follow-up study. Surg Endosc 2015;29:3698-711.

58. Shyr BU, Chen SC, Shyr YM, Wang SE. Learning curves for robotic pancreatic surgery-from distal pancreatectomy to pancreaticoduodenectomy. Medicine (Baltimore) 2018;97:e13000.

59. Van Heek NT, Kuhlmann KFD, Scholten RJ, de Castro SMM, Busch ORC, Van Gulik TM, et al. Hospital volume and mortality after pancreatic resection: a systematic review and an evaluation of intervention in the Netherlands. Ann Surg 2005;242:781-90.

60. Schmidt CM, Turrini O, Parikh P, House MG, Zyromski NJ, Nakeeb A, et al. Effect of hospital volume, surgeon experience, and surgeon volume on patient outcomes after pancreaticoduodenectomy. Arch Surg 2010;145:634-40.

61. Sharpe SM, Talamonti MS, Wang CE, Prinz RA, Roggin KK, Bentrem DJ, et al. Early national experience with laparoscopic pancreaticoduodenectomy for ductal adenocarcinoma: a comparison of laparoscopic pancreaticoduodenectomy and open 
pancreaticoduodenectomy from the National Cancer Data Base. J Am Coll Surg 2015;221:175-84.

62. Torphy RJ, Friedman C, Halpern A, Chapman BC, Ahrendt SS, McCarter MM, et al. Comparing short-term and oncologic outcomes of minimally invasive versus open pancreaticoduodenectomy across low and high volume centers. Ann Surg 2019;270:1147-55.

63. Wang Y, Bergman S, Piedimonte S, Vanounou T. Bridging the gap between open and minimally invasive pancreaticoduodenectomy: the hybrid approach. Can J Surg 2014;57:263-70.

64. Speicher PJ, Nussbaum DP, White RR, Zani S, Mosca PJ, Blazer III DG, et al. Defining the learning curve for team-based laparoscopic pancreaticoduodenectomy. Ann Surg Oncol 2014;21:4014-9.

65. Tan JKH, Ng JJ, Yeo M, Koh FHX, Bonney GK, Ganpathi IS, et al. Propensity score-matched analysis of early outcomes after laparoscopic-assisted versus open pancreaticoduodenectomy. ANZ J Surg 2019;89:E190-4.

66. Low TY, Koh YX, Goh BKP. First experience with robotic pancreatoduodenectomy in Singapore. Singapore Med J 2019; doi:10.11622/smedj.2019119.
67. Das De S, Kow AWC, Liau KH, Lim KH, Ho CK. Novel approach to laparoscopic resection of tumours of the distal pancreas. ANZ J Surg 2009;79:288-93.

68. Goh BKP, Lee SY, Kam JH, Soh HL, Cheow PC, Chow PKH, et al. Evolution of minimally invasive distal pancreatectomies at a single institution. J Minim Access Surg 2018;14:140-5.

69. Goh BKP, Low TY, Koh YX, Lee SY, Teo JY, Kam JH, et al. Changing trends and outcomes associated with the adoption of minimally invasive pancreatic surgeries: a single institution experience with 150 consecutive procedures in Southeast Asia. J Minim Access Surg 2019; doi:10.4103/jmas.JMAS_127_19.

70. Lee LS, Wong JS, Chiow AK, Lee SY, Chan CY, Tan SS, et al. The development of robotic hepatopancreatobiliary surgery in Singapoere: a multi-institutional experience. Ann Laparosc Endosc Surg 2018;3:59.

71. Liu R, Wakabayashi G, Palanivelu C, Tsung A, Yang K, Goh BKP, et al. International consensus statement on robotic pancreatic surgery. Hepatobiliary Surg Nutr 2019;8:345-60. 